\title{
Highly Pathogenic Reassortant Avian Influenza A(H5N1) Virus Clade 2.3.2.1a in Poultry, Bhutan
}

\author{
Atanaska Marinova-Petkova, ${ }^{1,2}$ John Franks, ${ }^{1}$ \\ Sangay Tenzin, Narapati Dahal, Kinzang Dukpa, \\ Jambay Dorjee, Mohammed M. Feeroz, \\ Jerold E. Rehg, Subrata Barman, Scott Krauss, \\ Pamela McKenzie, Richard J. Webby, \\ Robert G. Webster
}

Highly pathogenic avian influenza $\mathrm{A}(\mathrm{H} 5 \mathrm{~N} 1)$, clade 2.3.2.1a, with an H9-like polymerase basic protein 1 gene, isolated in Bhutan in 2012, replicated faster in vitro than its H5N1 parental genotype and was transmitted more efficiently in a chicken model. These properties likely help limit/eradicate outbreaks, combined with strict control measures.

$I^{\prime}$ $\mathrm{n}$ India and Bangladesh, highly pathogenic avian influenza (HPAI) A(H5N1) viruses of the 2.3.2.1a genetic lineage have circulated in poultry since 2011 (1-3). Subtype $\mathrm{H} 5 \mathrm{~N} 1$ endemicity is complicated by co-circulating subtype H9N2, G1_Mideast lineage $(4,5)$, which derives 5 internal genes from HPAI A(H7N3) virus from Pakistan (4). A reassortant H5N1 2.3.2.1a virus, rH5N1, with an H9N2-like polymerase basic protein 1 (PB1) gene (H7N3 origin), was reported in Bangladesh $(2,5,6)$, India, and Nepal (7). However, its virulence and transmissibility are undetermined.

In Bhutan, the poultry sector consists of free-range backyard chickens, a rising number of commercial chicken farms, and domestic waterfowl in the south $(8,9)$. Live-bird markets do not exist, but live birds are imported from India $(8,9)$.

Bhutan's poultry sector was severely affected by outbreaks of HPAI $\mathrm{A}(\mathrm{H} 5 \mathrm{~N} 1)$ clade 2.3.2.1 virus infection during 2012-2013 (10). Veterinary authorities enforced strict control measures, including depopulation of poultry in affected regions and burning of related housing and equipment (11). Illegal movement of poultry was the major source of outbreaks (11). Although the introduction of

Author affiliations: St. Jude Children's Research Hospital, Memphis, Tennessee, USA (A. Marinova-Petkova, J. Franks, J.E. Rehg, S. Barman, S. Krauss, P. McKenzie, R.J. Webby, R.G. Webster); National Centre for Animal Health, Ministry of Agriculture and Forests, Thimphu, Bhutan (S. Tenzin, N. Dahal, K. Dukpa, J. Dorjee); Jahangirnagar University, Dhaka,

Bangladesh (M.M. Feeroz)

DOI: http://dx.doi.org/10.3201/eid2212.160611
HPAI A(H5N1) from neighboring H5N1-endemic countries is a constant threat, the subtype is not yet entrenched in poultry in Bhutan.

\section{The Study}

We isolated HPAI A(H5N1) viruses from samples from 36 chickens and 9 wild birds in Bhutan, all from affected backyard farms adjacent to the highway connecting India with the capital, Thimphu (Figure 1; online Technical Appendix 1 Table 1, http://wwwnc.cdc.gov/EID/article/22/12/160611-Techapp1.pdf). Phylogenetic analysis (online Technical Appendix 1) suggested that the 2012-2013 outbreaks in Bhutan were caused by the rH5N1 genotype (2.3.2.1a/ H9-like PB1 [H7N3 origin]), reported in Bangladesh and India at that time (online Technical Appendix 1 Figures 1, 2; other data not shown). PB1 phylogeny suggested that this genotype underwent 4 independent reassortment events on the Indian subcontinent (online Technical Appendix 1 Figure 2).

Antigenic analysis of selected $\mathrm{H} 5 \mathrm{~N} 1$ isolates from Bhutan (online Technical Appendix 1) showed homogeneity and a reactivity pattern similar to that of $\mathrm{H} 5 \mathrm{~N} 1$ reference viruses from Bangladesh (Table). Amino acid differences were observed between strains A/chicken/ Bhutan/346/2012 (Ck/Bh/346) (rH5N1) and A/chicken/ Bangladesh/22478/2014 (Ck/BD/22478), representing the parental H5N1 clade 2.3.2.1a genotype (pH5N1) (online Technical Appendix 1 Table 2).

To assess whether the rH5N1-PB1 gene conferred a fitness advantage over the pH5N1 genotype, we examined replication kinetics in vitro (online Technical Appendix 1). The replication patterns of $\mathrm{rH} 5 \mathrm{~N} 1$ and $\mathrm{pH} 5 \mathrm{~N} 1$ were similar in Madin-Darby canine kidney (mammalian) cells (Figure 2, panel A). However, in chicken embryo fibroblasts (CEFs), Ck/Bh/346 (rH5N1) titers were significantly higher than those of Dk/BD/21326 (rH5N1) $(\mathrm{p}<0.05)$ and $\mathrm{Ck} / \mathrm{BD} / 22478(\mathrm{pH} 5 \mathrm{~N} 1) \quad(\mathrm{p}<0.01)$ at 12 hours postinoculation (hpi) and those of $\mathrm{Ck} / \mathrm{BD} / 22478$ (pH5N1) $(\mathrm{p}<0.001)$, and Dk/BD/19097 $(\mathrm{pH} 5 \mathrm{~N} 1)(\mathrm{p}<0.01)$ at 24 hpi. Dk/BD/21326 (rH5N1) had significantly higher titers than $\operatorname{did} \mathrm{Ck} / \mathrm{BD} / 22478(\mathrm{pH} 5 \mathrm{N1})(\mathrm{p}<0.01)$ at $24 \mathrm{hpi}$

${ }^{1}$ These authors contributed equally to this article.

${ }^{2}$ Current affiliation: Centers for Disease Control and Prevention, Atlanta, Georgia, USA. 


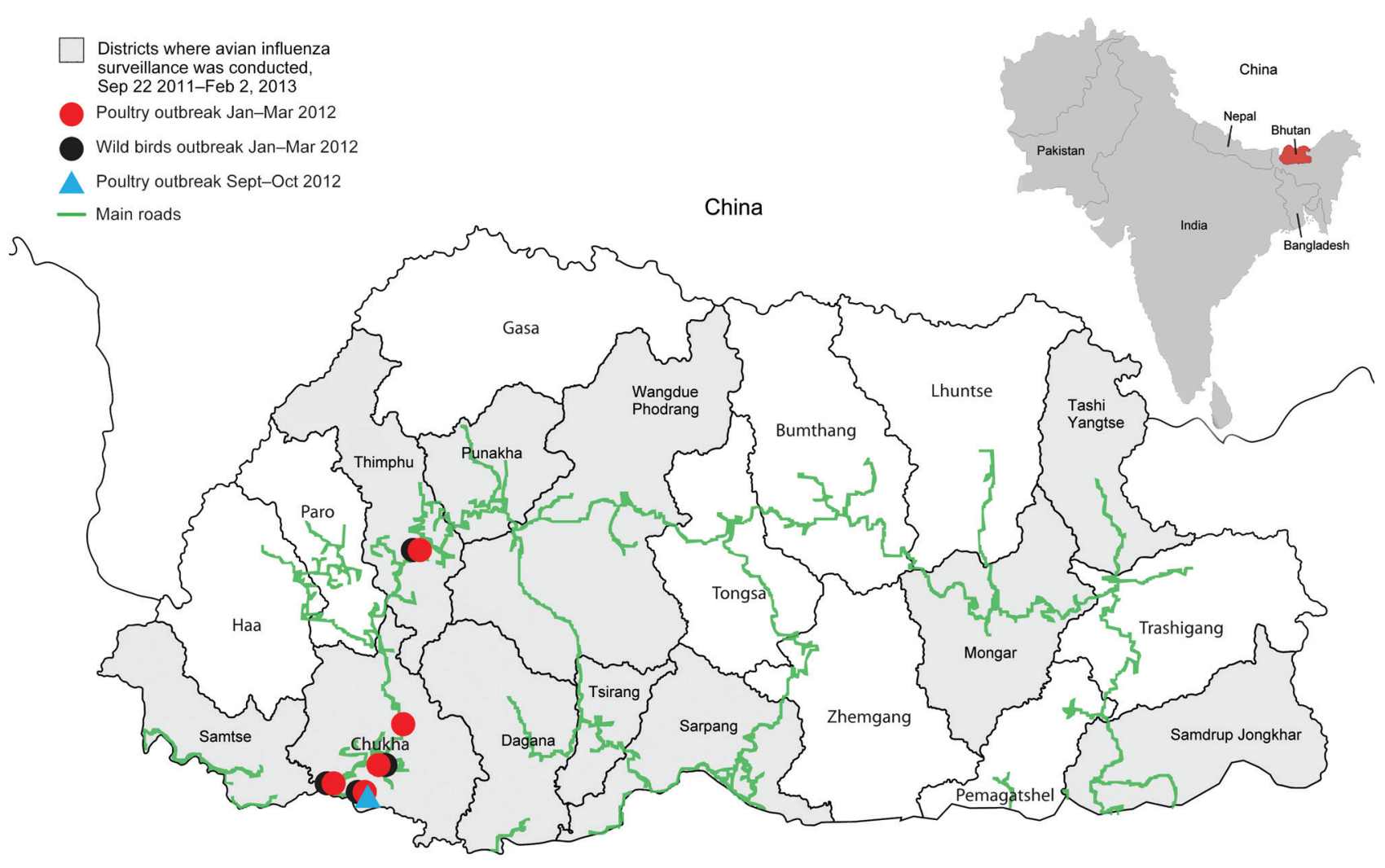

India
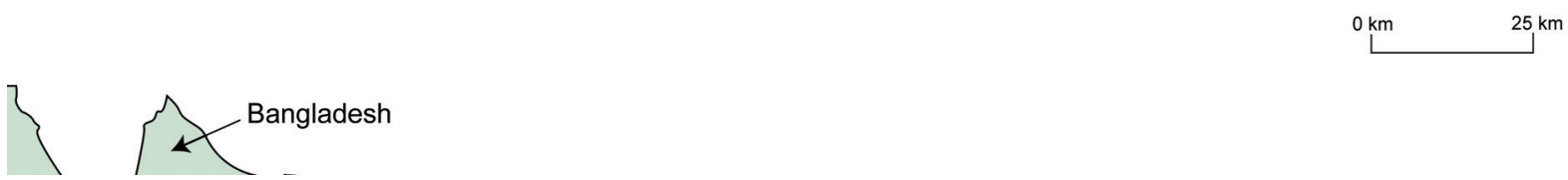

Figure 1. Locations of outbreaks of highly pathogenic avian influenza (H5N1) virus, Bhutan, 2011-2013.

(Figure 2, panel B). These results suggest $\mathrm{rH} 5 \mathrm{~N} 1$ viruses have a selective growth advantage in avian cells at early time points.

Next, we examined whether this growth advantage reflected higher pathogenicity or transmissibility for $\mathrm{Ck} / \mathrm{Bh} / 346$ (rH5N1) in chickens than did $\mathrm{Ck} / \mathrm{BD} / 22478$ (pH5N1) (online Technical Appendix 1). The 50\% lethal dose $\left(\mathrm{LD}_{50}\right)$ for chicken was $16 \mathrm{EID}_{50}(50 \%$ egg infective dose) for $\mathrm{Ck} / \mathrm{Bh} / 346(\mathrm{rH} 5 \mathrm{~N} 1)$ and $50 \mathrm{EID}_{50}$ for $\mathrm{Ck} /$ $\mathrm{BD} / 22478$ (pH5N1). After inoculation with $30 \mathrm{LD}_{50}$ and cohousing with naive contacts, all donors shed virus oropharyngeally and cloacally (Figure 2, panels C, D). All $\mathrm{Ck} / \mathrm{Bh} / 346$ (rH5N1) donors died within $48 \mathrm{hpi}$, whereas only $50 \%$ of chickens inoculated with $\mathrm{Ck} / \mathrm{BD} / 22478$ (pH5N1) died. Naive chickens in contact with donors inoculated with $\mathrm{Ck} / \mathrm{Bh} / 346(\mathrm{rH} 5 \mathrm{~N} 1)$ or $\mathrm{Ck} / \mathrm{BD} / 22478$ (pH5N1) became infected by day 2 after contact (Figure 2, panel C), started shedding cloacally on day 3 (Figure 2, panel D), and died by day 4 . On day 3 after contact,
$\mathrm{Ck} / \mathrm{Bh} / 346$ (rH5N1) contacts had oropharyngeal and cloacal titers $>1 \log _{10} \mathrm{EID}_{50} / \mathrm{mL}$ higher than those of $\mathrm{Ck} /$ BD/22478 (pH5N1) contacts (Figure 2, panels C, D), but the difference was not significant.

We placed $\mathrm{Ck} / \mathrm{Bh} / 346(\mathrm{rH} 5 \mathrm{~N} 1)$ and $\mathrm{Ck} / \mathrm{BD} / 22478$ (pH5N1) in direct competition by co-housing chickens inoculated with each virus with naive contacts (online Technical Appendix 1). All donors shed virus oropharyngeally and cloacally, starting at 1 day postinoculation (dpi). By day 3 after contact, real-time reverse transcription PCR to detect PB1 (online Technical Appendix 1) revealed that 7 of 8 naive contacts simultaneously exposed to both viruses were infected with $\mathrm{Ck} / \mathrm{Bh} / 346$ (rH5N1) alone, none was infected with $\mathrm{Ck} / \mathrm{BD} / 22478$ (pH5N1) alone, and 1 was co-infected with both viruses. Thus, despite the lower infectious dose used for $30 \mathrm{LD}_{50}, \mathrm{Ck} / \mathrm{Bh} / 346$ (rH5N1) killed inoculated chickens faster than $\mathrm{did} \mathrm{Ck} / \mathrm{BD} / 22478$ (pH5N1) and was transmitted faster and more efficiently to naive contacts. 
Table. Results of hemagglutination inhibition assays of highly pathogenic avian influenza H5N1 viruses isolated in Bhutan, 2012*

\begin{tabular}{|c|c|c|c|c|c|c|}
\hline \multirow[b]{2}{*}{ Antigens } & \multirow[b]{2}{*}{$\begin{array}{l}\text { Genetic } \\
\text { clade }\end{array}$} & \multicolumn{5}{|c|}{ Postinfection ferret antisera } \\
\hline & & $\begin{array}{c}\alpha- \\
\text { A/BHG/QH/IA } \\
\text { clade } 2.2\end{array}$ & $\begin{array}{c}\alpha- \\
\text { A/Hubei/1/2010 } \\
\text { clade 2.3.2.1a } \\
\end{array}$ & $\begin{array}{c}\alpha- \\
\text { A/ck/BD/15205 } \\
\text { clade 2.3.2.1a } \\
\end{array}$ & $\begin{array}{c}\alpha- \\
\text { A/dk/BD/19097 } \\
\text { clade 2.3.2.1a† }\end{array}$ & $\begin{array}{c}\alpha- \\
\text { A/ck/Bhutan/346 } \\
\text { clade 2.3.2.1a† }\end{array}$ \\
\hline \multicolumn{7}{|l|}{ Reference antigens } \\
\hline A/BHG/QH/IA & 2.2 & 320 & 40 & 40 & 80 & 40 \\
\hline A/Hubei/1/2010 & 2.3.2.1a & 40 & 640 & 160 & 1280 & 80 \\
\hline $\mathrm{A} / \mathrm{ck} / \mathrm{BD} / 15205$ & 2.3.2.1a & 10 & 80 & 80 & 320 & 40 \\
\hline A/dk/BD/19097 & 2.3.2.1a & - & 40 & 80 & 320 & 40 \\
\hline A/ck/Bhutan/346 & 2.3.2.1a & 10 & 40 & 80 & 640 & 80 \\
\hline \multicolumn{7}{|l|}{ Test antigens } \\
\hline A/chicken/Bhutan/257/2012 & 2.3.2.1a & 20 & 40 & 40 & 640 & 40 \\
\hline A/chicken/Bhutan/260/2012 & 2.3.2.1a & 20 & 40 & 80 & 640 & 80 \\
\hline A/wild bird/Bhutan/357/2012 & 2.3.2.1a & 20 & 40 & 80 & 640 & 40 \\
\hline A/chicken/Bhutan/1026/2012 & 2.3.2.1a & 40 & 40 & 80 & 1280 & 80 \\
\hline A/chicken/Bhutan/1030/2012 & 2.3.2.1a & 80 & 160 & 320 & 1280 & 320 \\
\hline A/chicken/Bhutan/317/2012 & 2.3.2.1a & 10 & 40 & 80 & 640 & 80 \\
\hline A/wild bird/Bhutan/326/2012 & 2.3.2.1a & 10 & 80 & 40 & 320 & 20 \\
\hline A/wild bird/Bhutan/328/2012 & 2.3.2.1a & 40 & 20 & 40 & 640 & 80 \\
\hline A/wild bird/Bhutan/356/2012 & 2.3.2.1a & 40 & 160 & 160 & 640 & 80 \\
\hline A/chicken/Bhutan/406/2012 & 2.3.2.1a & 20 & 40 & 80 & 320 & 80 \\
\hline A/chicken/Bhutan/413/2012 & 2.3.2.1a & 20 & 40 & 80 & 640 & 40 \\
\hline A/chicken/Bhutan/505/2012 & 2.3.2.1a & 80 & 40 & 80 & 640 & 80 \\
\hline A/chicken/Bhutan/933/2012 & 2.3.2.1a & 40 & 40 & 80 & 640 & 80 \\
\hline \multicolumn{2}{|l|}{ GMT $(95 \%$ Cl) } & $\begin{array}{c}27.54 \\
(18.36-41.30)\end{array}$ & $\begin{array}{c}49.51 \\
(34.61-70.83)\end{array}$ & $\begin{array}{c}80 \\
(56.83-112.6)\end{array}$ & $\begin{array}{c}640 \\
(502.5-815.1)\end{array}$ & $\begin{array}{c}68.17 \\
(46.24-100.5)\end{array}$ \\
\hline $\begin{array}{l}\text { *Boldface indicates homologous tite } \\
\text { A/ck/Bhutan/346, A/chicken/Bhutan/ } \\
\text { †The immune response in ferrets wa }\end{array}$ & $\mathrm{BHG} / \mathrm{QH} / \mathrm{l}$ & A/bar-headed goc & $\begin{array}{l}\text { se/Qinghai/IA/2005 } \\
\text { angladesh/19097/2 } \\
\text { adjuvant (InvivoGe }\end{array}$ & $\mathrm{A} / \mathrm{ck} / \mathrm{BD} / 15205, \mathrm{~A} / \mathrm{c}$ & $\begin{array}{l}\text { icken/Bangladesh/ } \\
\text { mean titer. }\end{array}$ & $5205 / 2012$ \\
\hline
\end{tabular}

We assessed the risk for human infection with rH5N1 by investigating its pathogenicity and transmissibility in ferrets (online Technical Appendix 1). Donors shed $4.5 \log _{10} \mathrm{EID}_{50} / \mathrm{mL}$ and $3.4 \log _{10} \mathrm{EID}_{50} / \mathrm{mL}$ in nasal wash samples at 2 dpi and $4 \mathrm{dpi}$, respectively, but cleared the virus by $6 \mathrm{dpi}$. No direct or aerosol contacts shed virus, suggesting that $\mathrm{Ck} / \mathrm{Bh} / 346$ (rH5N1) was not transmitted (data not shown). No Ck/Bh/346 (rH5N1)-inoculated ferrets lost $>5 \%$ of their body weight or showed elevated body temperature (data not shown). Histopathologic analysis showed that 1 donor, who was lethargic at 3-10 dpi, had mild meningoencephalitis at $14 \mathrm{dpi}$ (online Technical Appendix 2, http://wwwnc.cdc.gov/EID/ article/22/12/16-0611-Techapp2.pdf). A nucleocapsid protein-positive cell was detected in the brain, suggesting that $\mathrm{Ck} / \mathrm{Bh} / 346$ (rH5N1) is neurotropic. The other ferrets showed no clinical signs of disease. Virus replication was detected in the lung at $4 \mathrm{dpi}\left(\log _{10} 2.75 \mathrm{EID}_{50} / \mathrm{g}\right)$ (online Technical Appendix 2).

\section{Conclusions}

Our study revealed that the viruses that caused the 2012 outbreaks in Bhutan belonged to the rH5N1 genotype (2.3.2.1a/H9-like PB1 [7:1]), whereas neither H9N2 nor the $\mathrm{pH} 5 \mathrm{~N} 1$ genotype have been detected there. $\mathrm{rH} 5 \mathrm{~N} 1$ has been isolated sporadically at live-bird markets and from chickens on farms where outbreaks occurred in Bangladesh (5,6), India (12), and Nepal (7) in 2011-2013. The lack of data on the effect of the H9-like PB1 gene on the virulence of rH5N1 makes determining its pathogenicity and transmissibility a critical public-health goal for Bhutan and neighboring countries.

$\mathrm{Ck} / \mathrm{Bh} / 346$ (rH5N1) killed inoculated chickens faster than $\operatorname{did} \mathrm{Ck} / \mathrm{BD} / 22478(\mathrm{pH} 5 \mathrm{~N} 1)$, despite the lower infectious dose used for $\mathrm{Ck} / \mathrm{Bh} / 346$. In CEFs, $\mathrm{Ck} /$ $\mathrm{Bh} / 346$ replicated with greater efficiency during the first 36 hpi than did $\mathrm{Ck} / \mathrm{BD} / 22478$, which possibly explains why rH5N1 transmits more efficiently to naive chickens when directly competing with $\mathrm{pH} 5 \mathrm{~N} 1$. How faster replication contributes to the increased mortality rate of naive chickens might be crucial to eradicating the disease in Bhutan. In a mountainous region with widely separated villages, small-scale poultry farming, and no live-bird markets, the severity and rapid onset of the infection could lead to hostresource exhaustion and self-limitation.

To determine whether the reassortant PB1 gene accounts for the observed phenotypic properties of rH5N1, reverse genetics experiments are required. Despite its enhanced transmissibility, rH5N1 did not supplant pH5N1 in India or Bangladesh after undergoing multiple reassortment events. Possible reasons for this include the involvement of other influenza subtypes, which would complicate the competition/transmission model, especially at live-bird markets, as well as the large duck population, which is prone to inapparent HPAI infection (indicating possible underreporting). 

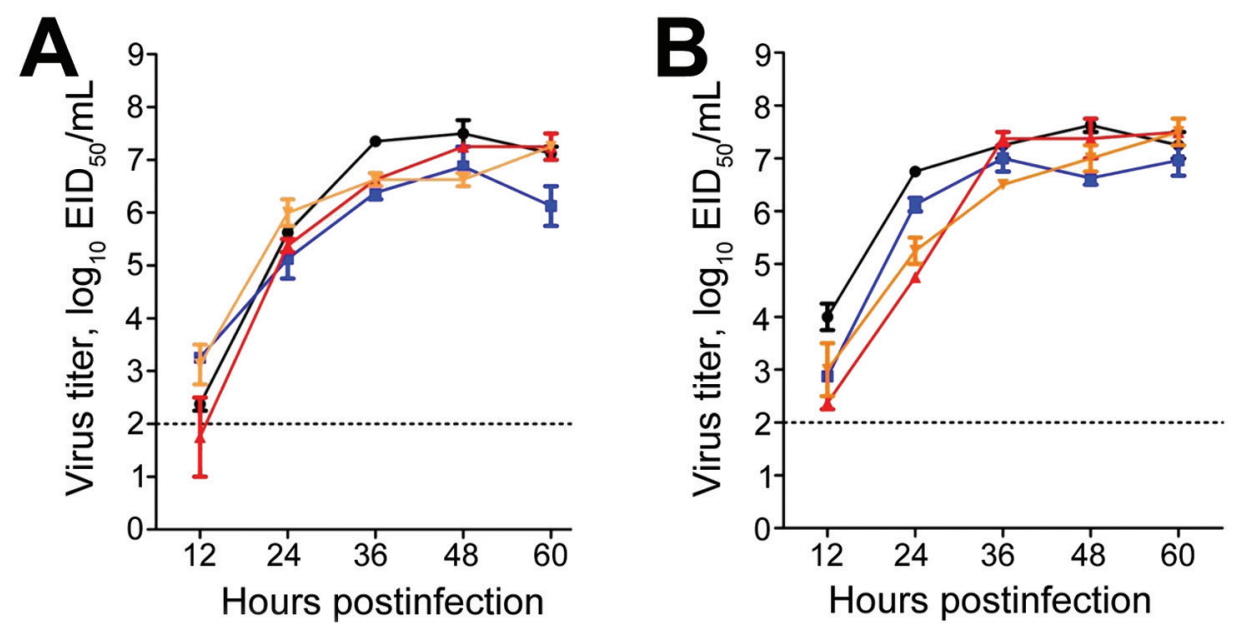

- $\mathrm{Ck} / \mathrm{Bh} / 346(\mathrm{rH} 5 \mathrm{~N} 1)$

$\Rightarrow \mathrm{DK} / \mathrm{BD} / 21326(\mathrm{rH} 5 \mathrm{~N} 1)$

$=\mathrm{Ck} / \mathrm{BD} / 22478(\mathrm{pH} 5 \mathrm{~N} 1)$

- Dk/BD/19097 (pH5N1)
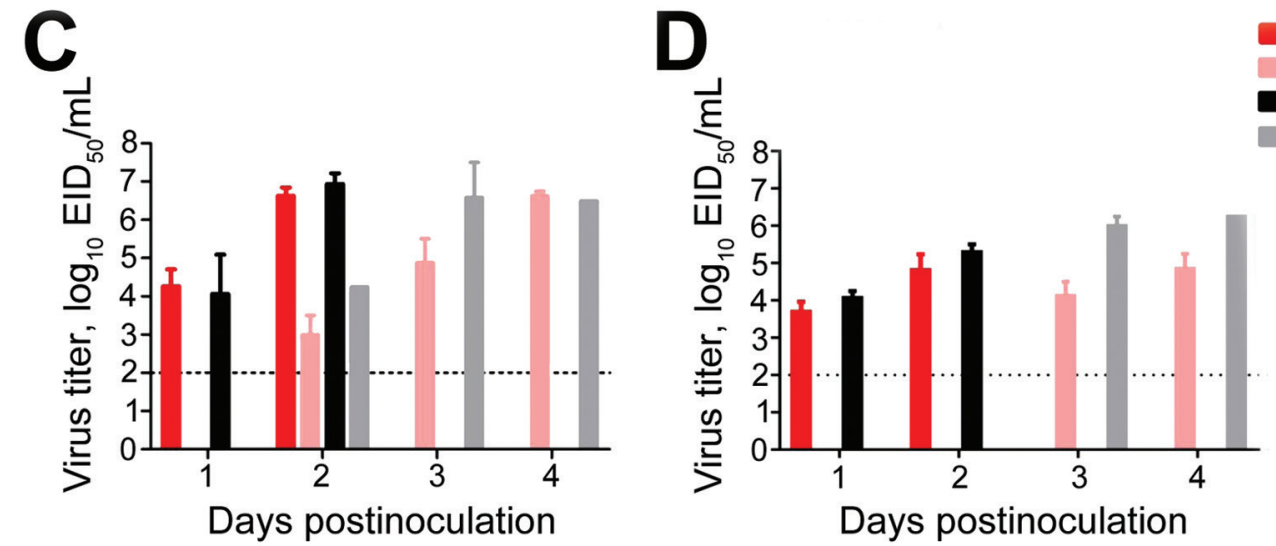

Figure 2. Pathogenesis of influenza virus rH5N1 and pH5N1 2.3.2.1a genotypes in vitro and in vivo. A) Replication kinetics of rH5N1 and pH5N1 in Madin-Darby canine kidney (mammalian) cells. B) Replication kinetics of rH5N1 and pH5N1 in chicken embryonic fibroblast (avian) cells. C) Oropharyngeal shedding and transmissibility of rH5N1 and pH5N1 in a single-virus transmission model in 5-week-old White Leghorn chickens. D) Cloacal shedding and transmissibility of rH5N1 and pH5N1 in a single-virus transmission model in 5-week-old White Leghorn chickens. Naive chickens were co-housed with donors infected with either Ck/22478 (pH5N1) or $\mathrm{Ck} / \mathrm{Bh} / 346$ ( $\mathrm{rH} 5 \mathrm{~N} 1)(\mathrm{C}$ and D). The dashed line in each panel represents the limit of virus detection. ANOVA, analysis of variance; Ck/22478, A/chicken/Bangladesh/22478; Ck/Bh/346, A/chicken/Bhutan/346/2012; Dk/BD/23126, A/duck/Bangladesh/23126; Dk/ BD/19097/2013, A/duck/Bangladesh/19097; EID, egg infectious dose; dpi, days postinoculation; hpi, hours postinfection; pH5N1, pandemic H1N1; rH5N1, reassortant H5N1.

Our ferret model results suggest that avian-to-human transmission of rH5N1 is possible. However, further adaptation to the host is necessary for rH5N1 to become transmissible among mammals. Similar results have been reported for H5N1 clade 2.3.2.1 (13), H5N1 clade 2.3.4 (14), and H5Nx clade 2.3.4.4 (15). rH5N1 is potentially neurotropic, manifesting clinically as mild meningoencephalitis with no obvious respiratory involvement. This finding has implications on early diagnosis and use of antiviral drugs during the first 48 hours after clinical diagnosis for optimal therapeutic effect.

pH5N1 and H9N2 virus strains will likely continue to co-circulate on the Indian subcontinent, enabling further reassortment events. Our results highlight the need for active surveillance and full-genome sequencing of all H5N1 virus isolates.

\section{Acknowledgments}

We thank M. Kamrul Hasan, Sharmin Akhtar, and Jasmine Turner for technical support; Lisa Kercher, Beth Little, and David Carey for help in the enhanced animal Biosafety Level 3 laboratory during animal experiments; James Knowles for administrative support; Elizabeth Stevens for generating Figure 1; Jeremy Jones for critically reviewing the manuscript; and Vani Shanker and Keith A. Laycock for scientific editing.

This work was funded by contracts HHSN266200700005C and HHSN272201400006C from the National Institute of Allergy and Infectious Diseases, the National Institutes of Health, and the Department of Health and Human Services, and by the American Lebanese Syrian Associated Charities. 
Dr. Marinova-Petkova was a postdoctoral research associate at St. Jude Children's Research Hospital, Memphis, Tennessee, USA, while this research was conducted. She is now affiliated with the Centers for Disease Control and Prevention, Atlanta, Georgia, USA, where her research interests include emerging influenza viruses at the animal-human interface, the evolution of influenza A viruses, and animal models for studying influenza pathogenesis and transmission.

\section{References}

1. Nagarajan S, Tosh C, Smith DK, Peiris JSM, Murugkar HV, Sridevi R, et al. Avian influenza (H5N1) virus of clade 2.3.2 in domestic poultry in India. PLoS ONE. 2012;7:e31844. http://dx.doi.org/10.1371/journal.pone.0031844

2. Gerloff NA, Khan SU, Balish A, Shanta IS, Simpson N, Berman L, et al. Multiple reassortment events among highly pathogenic avian influenza $\mathrm{A}(\mathrm{H} 5 \mathrm{~N} 1)$ viruses detected in Bangladesh. Virology. 2014;450-451:297-307. http://dx.doi.org/10.1016/j.virol.2013.12.023

3. Marinova-Petkova A, Feeroz MM, Rabiul Alam SM, Kamrul Hasan M, Akhtar S, Jones-Engel L, et al. Multiple introductions of highly pathogenic avian influenza H5N1 into Bangladesh. Emerg Microbes Infect. 2014;3:e11. http://dx.doi.org/10.1038/emi.2014.11

4. Shanmuganatham K, Feeroz MM, Jones-Engel L, Smith GJD, Fourment M, Walker D, et al. Antigenic and molecular characterization of avian influenza $\mathrm{A}(\mathrm{H} 9 \mathrm{~N} 2)$ viruses, Bangladesh. Emerg Infect Dis. 2013;19. Epub 2013 Sep. http://dx.doi.org/10.3201/eid1909.130336

5. Marinova-Petkova A, Shanmuganatham K, Feeroz MM, Jones-Engel L, Hasan MK, Akhtar S, et al. The continuing evolution of H5N1 and H9N2 influenza viruses in Bangladesh between 2013 and 2014. Avian Dis. 2016;60(Suppl):108-17. http://dx.doi.org/10.1637/11136-050815-Reg

6. Monne I, Yamage M, Dauphin G, Claes F, Ahmed G, Giasuddin M, et al. Reassortant avian influenza A(H5N1) viruses with H9N2-PB1 gene in poultry, Bangladesh. Emerg Infect Dis. 2013;19. http://dx.doi.org/10.3201/eid1910.130534
7. Benson DA, Karsch-Mizrachi I, Lipman DJ, Ostell J, Wheeler DL. GenBank. Nucleic Acids Res. 2005;33:D34-8. http://dx.doi.org/10.1093/nar/gki063

8. Nidup K, Tshering P. Status of the family poultry production and HPAI in Bhutan. In: Proceedings of the 8th Asian Pacific Poultry Conference of the World's Poultry Science Association; Bangkok, Thailand; March 2007. p. 78-83 [cited 2016 Mar 8]. http://cms.cnr.edu.bt/cms/files/docs/File/Karma\%20Nidup/Poultry/ FamilyPoultry\&HPAIinBhutan.pdf

9. Ministry of Agriculture and Forests of the Royal Government of Bhutan. Bhutan RNR statistics, 2015 [cited 2016 Mar 8]. http://www.moaf.gov.bt/bhutan-rnr-statistics-2015-online/

10. World Organisation for Animal Health. Update on highly pathogenic avian influenza in animals (type $\mathrm{H} 5$ and $\mathrm{H} 7$ ). Immediate notification report, Bhutan. 2012 [cited 2016 Feb 8]. https://web. oie.int/wahis/reports/en_imm_0000011465_20120110_120756.pdf

11. Ministry of Agriculture and Forests of Bhutan. RNR newsletter. 2013; I(3) [cited 2016 Feb 8]._http://www.moaf.gov.bt/rnr-newsletterseptember-2013/

12. Bhat S, Bhatia S, Pillai AS, Sood R, Singh VK, Shrivas OP, et al Genetic and antigenic characterization of $\mathrm{H} 5 \mathrm{~N} 1$ viruses of clade 2.3.2.1 isolated in India. Microb Pathog. 2015;88:87-93. http://dx.doi.org/10.1016/j.micpath.2015.08.010

13. Xu L, Bao L, Yuan J, Li F, Lv Q, Deng W, et al. Antigenicity and transmissibility of a novel clade 2.3.2.1 avian influenza H5N1 virus. J Gen Virol. 2013;94:2616-26. http://dx.doi.org/10.1099/vir.0.057778-0

14. Sun H, Pu J, Wei YD, Sun Y, Hu J, Liu L, et al. Highly pathogenic avian influenza $\mathrm{H} 5 \mathrm{~N} 6$ viruses exhibit enhanced affinity for human type sialic acid receptor and in-contact transmission in model ferrets. J Virol. 2016. Epub 2016 Apr 27. http://dx.doi.org/10.1128/JVI.00127-16

15. Pulit-Penaloza JA, Sun X, Creager HM, Zeng H, Belser JA, Maines TR, et al. Pathogenesis and transmission of novel highly pathogenic avian influenza $\mathrm{H} 5 \mathrm{~N} 2$ and $\mathrm{H} 5 \mathrm{~N} 8$ viruses in ferrets and mice. J Virol. 2015;89:10286-93. http://dx.doi.org/10.1128/JVI.01438-15

Address for correspondence: Robert G. Webster, Department of Infectious Diseases, MS 330, St. Jude Children's Research Hospital, 262 Danny Thomas P1, Memphis, TN 38105-3678, USA; email: robert.webster@stjude.org

\section{World AIDS Day, December 1

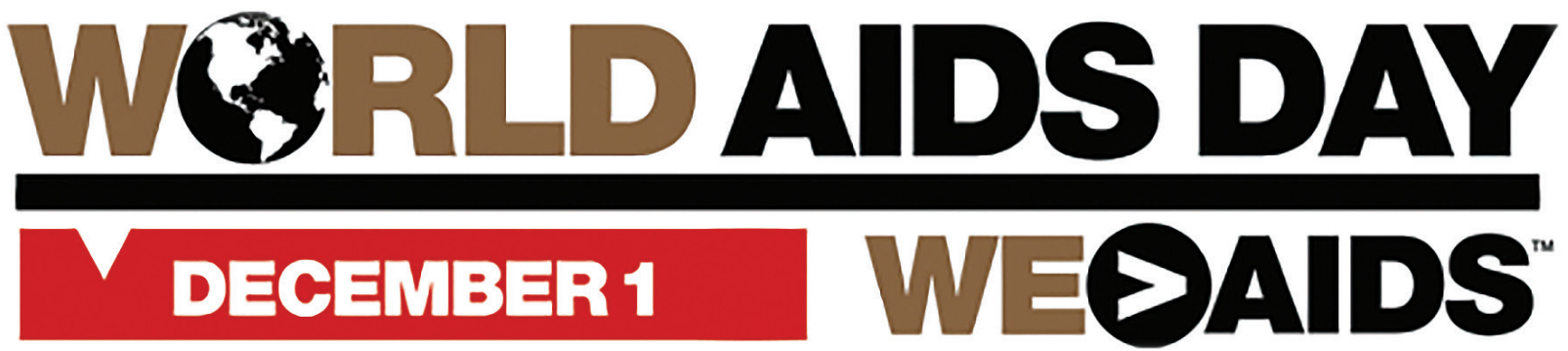 \\ December 1 is World AIDS Day, an opportunity for people to work actively and collaboratively with partners around the world to raise awareness about HIV and help us move closer to the goal of an AIDS-free generation. http://wwwnc.cdc.gov/eid/page/world-aids

